\title{
Design and validation of an online partial and total pressure measurement system for Li-ion cells
}

\author{
Robin Lundström, Erik J. Berg \\ Department of Chemistry, Ångström Laboratory, Uppsala University, Box 538, SE-751 21, Uppsala, Sweden
}

\section{H I G H L I G H T S}

- Development of both partial and total pressure measurements for Li-ion cells.

- Detailed gas evolution study of a classical $\mathrm{Li}$-ion $\mathrm{LiCoO}_{2} / \mathrm{Graphite}$ cell.

- Decoupling reactions associated with SEI formation and $\mathrm{LiCoO}_{2} /$ electrolyte interface.

- $\mathrm{O}_{2}$ release from $\mathrm{Li}_{\mathrm{x}} \mathrm{CoO}_{2}$ depends on state of charge rather than electrode potential.

\section{A R T I C L E I N F O}

\section{Keywords:}

Li-ion batteries

$\mathrm{LiCoO}_{2}$ decomposition

Gas evolution

Side-reactions

Online electrochemical mass spectrometry

\begin{abstract}
A B S T R A C T
Online Electrochemical Mass Spectrometry (OEMS) provides unparalleled access to the details of electrode/ electrolyte interfacial reactions in electrochemical systems. Herein, the development and validation of an OEMS system along with detailed calibration protocols and limits of detection sensitivity are showcased. Combined partial and total pressure monitoring provides a clear advantage when detailing major and minor gas reactions as well as when determining unaccounted gases. A classical $\mathrm{Li}$-ion $\mathrm{LiCoO}_{2} / \mathrm{Graphite}$ full cell is studied during overcharge to $4.9 \mathrm{~V} v s$. $\mathrm{Li}^{+} / \mathrm{Li}$ at $50{ }^{\circ} \mathrm{C}$ at an unprecedented level of detail and the results are compared to $\mathrm{LiCoO}_{2} / \mathrm{LiFePO}_{4}$ and $\mathrm{Graphite} / \mathrm{LiFePO}_{4}$ cells in order to differentiate between gases forming at the anode and cathode. The release of $\mathrm{O}_{2}$ from $\mathrm{Li}_{\mathrm{x}} \mathrm{CoO}_{2}(\mathrm{x}<0.4)$ during both charge and discharge demonstrates that its degradation is dependent on state of charge 1-x rather than potential. The presented methodology establishes an improved experimental basis for deeper understanding of interfacial reactions in batteries and electrochemical systems alike.
\end{abstract}

\section{Introduction}

The lifetime of Li-ion batteries is determined by the nature and extent of side-reaction processes in battery cells. These processes are complex thermal- and electric potential-triggered chain-reactions involving solid, liquid and gaseous reactants and products. Deeper understanding of these reactions, especially the intermediate nonequilibrium steps, has therefore to rely on operando characterization. However, considering that a state-of-the-art Li-ion cell exhibits a coulombic efficiency $>99.97 \%(\sim 300 \mathrm{ppm}$ of the total number of reactions occurring in the cell per time unit are irreversible), identification and quantification of these very minor side-reactions are a challenge. New sophisticated analytical methodologies of high selectivity and sensitivity are clearly necessary. One among few techniques addressing such a need is mass spectrometry (MS) and the development and application thereof have been intense during the past hundred years [1]. Today, MS comes in a rich spectrum of flavors and its interface to neighboring analytical techniques and scientific disciplines, such as electrochemistry, attracts significant attention. A highly successful and promising, yet under-developed approach is online (alternatively called differential, operando or real-time) electrochemical MS developed for the study of electrode potential-induced reactions [2-7].

The use of MS to investigate gas evolution in electrochemical applications was first done in 1971 by Gadde and Bruckenstein, who studied generation of $\mathrm{O}_{2}$ from $\mathrm{HClO}_{4}$ [8]. Online gas analysis was later developed and applied in the field of electrocatalysis in 1984 by Wolter and Heitbaum, and was given the name differential electrochemical MS (DEMS) [9]. The term differential was allegedly added to point out that

\footnotetext{
* Corresponding author.

E-mail address: erik.berg@kemi.uu.se (E.J. Berg).
} 
the gaseous products were extracted from the cell immediately upon formation via a differentially pumped gas inlet system to the mass spectrometer (MS). The working electrode was in close contact with a hydrophobic membrane (porous PTFE), which acted as a MS inlet separating the aqueous electrolyte from the vacuum. Although the thin membrane lets the less polar reaction products $\mathrm{O}_{2}$ and $\mathrm{CO}_{2}$ rapidly diffuse through (response time $\sim 0.1 \mathrm{~s}$ ) $[3,10]$, the continuous diffusion and evaporation of volatile $\mathrm{H}_{2} \mathrm{O}$ solvent into the vacuum of the MS gradually changes the electrolyte composition and compromises longer-term cycling. Imhof and Novák applied a similar DEMS methodology to Li-ion cell chemistry in 1998 and demonstrated the temporal evolution of $\mathrm{C}_{2} \mathrm{H}_{4}$ and $\mathrm{H}_{2}$ as result of solid electrolyte interphase (SEI) formation on the carbonaceous negative electrode [6]. Since then, cell designs and gas inlets to the MS have been improved, resulting in higher electrochemical performance as well as improved selectivity and sensitivity for gas analysis. In 2005 Novák et al. [11] developed an electrochemical cell with an open headspace, to which the evolving gases could diffuse and be immediately carried to the inlet of the MS via a continuous flow of Ar. Probing the gaseous phase of the cell leads to significantly lower electrolyte induced background in the MS with higher sensitivity for the various reaction products as a result. The response time did however increase $(\sim 10 \mathrm{~s})$, which is acceptable considering time-scales for Li-ion cell cycling (hours to weeks). Berkes et al. [2] adapted the setup by including both a cold-trap (removing volatile electrolyte components) and an infrared spectrometer online in order to achieve a reduced electrolyte background in the MS and improve selectivity (primarily for carbon monoxide). A major upgrade was nevertheless the cell design, which closely mimicked a Li-ion coin cell with practical electrodes and a typical Li-ion separator. The tight electrode stack allowed however the evolving gases to escape only laterally, which effectively trapped or delayed the gas release with a significant loss of time resolution as a result.

During the upswing of Li-air batteries around year 2010, McCloskey et al. [5] developed a new DEMS setup based on a set of gas valves, which allowed for a semi-closed cell headspace only probed by the MS at discrete intervals (e.g. once every $10 \mathrm{~min}$ ). Avoiding the continuous flow of Ar carrier gas through the cell led not only to less depletion of the volatile part of the electrolyte, but also to a higher sensitivity because the gas could accumulate in-between every measurement point. The use of air electrodes with an open porosity towards the headspace of the cell significantly reduced the gas diffusion distance to the cell headspace. He et al. $[12,13]$ further developed the semi-closed approach with a larger cell design, different valves/seals, and comparable performance, but the investigations were focused on Li-ion cell chemistry. Gasteiger et al. made a similar journey from Li-air to gas analysis of Li-ion cells, but focused their efforts on a more simplified Online Electrochemical MS setup (OEMS) [4]. A closed cell headspace is directly connected to the MS with a metallic leak capillary without flow of an additional carrier gas. The sampling by the MS ( $1 \mu \mathrm{L} / \mathrm{min})$ leads on the other hand to a continuous drop in pressure of the cell limiting their experimental time typically $<48 \mathrm{~h}$. The experiment time can be extended by increasing the cell volume, but at the expense of the sensitivity. Keeping the evolved gases inside the cell is however a major advantage of such a closed (or integral approach as opposed to differential) cell approach as several gases, such as $\mathrm{CO}_{2}$, are well known to be consumed by subsequential reactions in practical Li-ion cells [14,15].

Herein, we build upon the work of He et al. and present an OEMS setup including an electrochemical cell, a gas sampling system, and a capillary inlet to the MS. Two proof-of-concept experiments are showcased, i.e. (I) sensitivity limitation test and (II) gas profiling during electrochemical testing of a $\mathrm{LiCoO}_{2}$ (LCO)/graphite (G) cell, with LCO/ $\mathrm{LiFePO}_{4}$ (LFP) and G/LFP cells as analytical support.

\section{Experimental}

\subsection{Setup}

The OEMS system described herein can be divided into three essential parts, (1) a dedicated electrochemical cell, (2) a cell sampling system, and (3) a MS - all illustrated in Fig. 1. The cell is designed in a coin-cell type configuration mainly consisting of a stainless steel bottom cup and top lid. A high-density polyethylene (HDPE, Christian Berner, Sweden) gasket electrically isolates the two parts and effectively seals the cell from gas leakage when compressed. The pressure on the gasket is applied by four screws inserted through the lid and tightly screwed to the cup holder made of polyoxymethylene. The lid has a gas outlet to sample the generated gas and an inlet to refill the cell with fresh Ar carrier gas. Both gas connections are kept closed by two manual valves when the cell is transported from assembly in an inert Ar atmosphere in a glovebox to be attached to the sampling system. A polyether ether ketone (PEEK, $\varnothing_{\mathrm{OD}} 28.9 \mathrm{~mm}, \varnothing_{\mathrm{ID}} 16 \mathrm{~mm}$ ) cylinder is placed inside the cup to reduce cell volume as well as to center a spring and electrodes. The spring $\left(\varnothing_{\mathrm{OD}} 15.5 \mathrm{~mm}, \varnothing_{\mathrm{ID}} 13.5 \mathrm{~mm}\right.$, Sodemann Industrifjedre A/S, Denmark) electronically connects the top working electrode to the cell lid and applies pressure to the electrode stack via a rigid stainless steel mesh $(212 / 90 \mu \mathrm{m}, \oslash 16 \mathrm{~mm}$, Bopp AG, Switzerland). The same mesh also serves as current collector for the working electrode, thus permitting gas and ions to diffuse freely throughout the electrode stack. The counter electrode is electronically connected to the bottom cell cup.

The sampling system comprises three volumes denoted cell volume (" $V_{c}$ ", $3.6 \mathrm{~mL}$ ), manifold volume (" $V_{m}$ ", $3.1 \mathrm{~mL}$ ), and analysis volume (" $V_{a}$ ", $1.14 \mathrm{~mL}$ ), each separated by miniature high-speed solenoid pressure valves ("SX", 24 V, Series 99, Parker, US). All gas connections are of Swagelok VCR type, sealed with silver-plated gaskets $\left(1 / 8^{\prime \prime}\right.$, SS-2VCR-2, US). Apart from the internal gas volume of the cell, $V_{c}$ comprises two manual valves (SS-4H, Swagelok), one straight- and one T-union, as well as a high-sensitivity pressure transducer (PAA-33X, Keller-Druck AG, Switzerland). One $1 / 8^{\prime \prime}$ gas pipe and three T-unions to which the calibration gases and Ar carrier gas (purity 99.9999\%, Air Liquide, France) are connected comprise $V_{m}$. A cross-union to which a root pump (ACP15, Pfeiffer, Germany) and a fused silica capillary MS gas inlet (flow rate $\sim 12 \mu \mathrm{L} / \mathrm{min}, \varnothing_{\mathrm{ID}} 50 \mu \mathrm{m}, \ell 1.5 \mathrm{~m}$, Trajan, Australia) are connected constitute $V_{a}$. Leak-proof seal of the latter part is achieved by an adapted VCR-Valco Vici union (ZU1M, Switzerland) containing a Valcon polyimide one-piece ferrule (FS1.25-5, Valco Vici). The mass spectrometer (QME220, Pfeiffer) utilizes a closed electron ionization source, quadrupole mass analyzer (1-200 amu) and a continuous secondary electron multiplier detector. The working pressure in the ionization chamber is kept at $\sim 6 \times 10^{-6}$ mbar during measurements, but pumped down to $\sim 10^{-8}$ mbar between each measurement point, utilizing a turbomolecular pump (HiCube80, Pfeiffer). The solenoid valves are controlled using a National Instruments NI-DAQ, operated with LabView 2018 (National Instruments, US). The sampling system and electrochemical cell are integrated inside a temperature-controlled incubator chamber (Tritec, Germany) for controlled temperature measurements.

\subsection{Calibration}

A volume (here $V_{c}, V_{a}$ and $V_{m}$ ) can generally be determined with the pressure transducer by solving Boyles law for $\mathrm{V}_{\mathrm{i}}$ :

$V_{i} P_{i}=P_{p+i}\left(V_{i}+V_{p}\right)$

The unknowns are determined by filling $V_{i}$ with Ar gas, recording $P_{i}$, then letting it expand into an evacuated $V_{p}$ of known volume and recording the subsequent pressure $P_{p+i}$. Both $V_{a}$ and $V_{m}$ were determined to be 1.14 and $3.1 \mathrm{~mL}$, respectively, by sequentially connecting precision tubes ( 1 and $5 \mathrm{~mL}$, SL1KCUW and SL5KCUW, Valco Vici). The same procedure, based on the already determined value of $V_{a}$, is employed for 

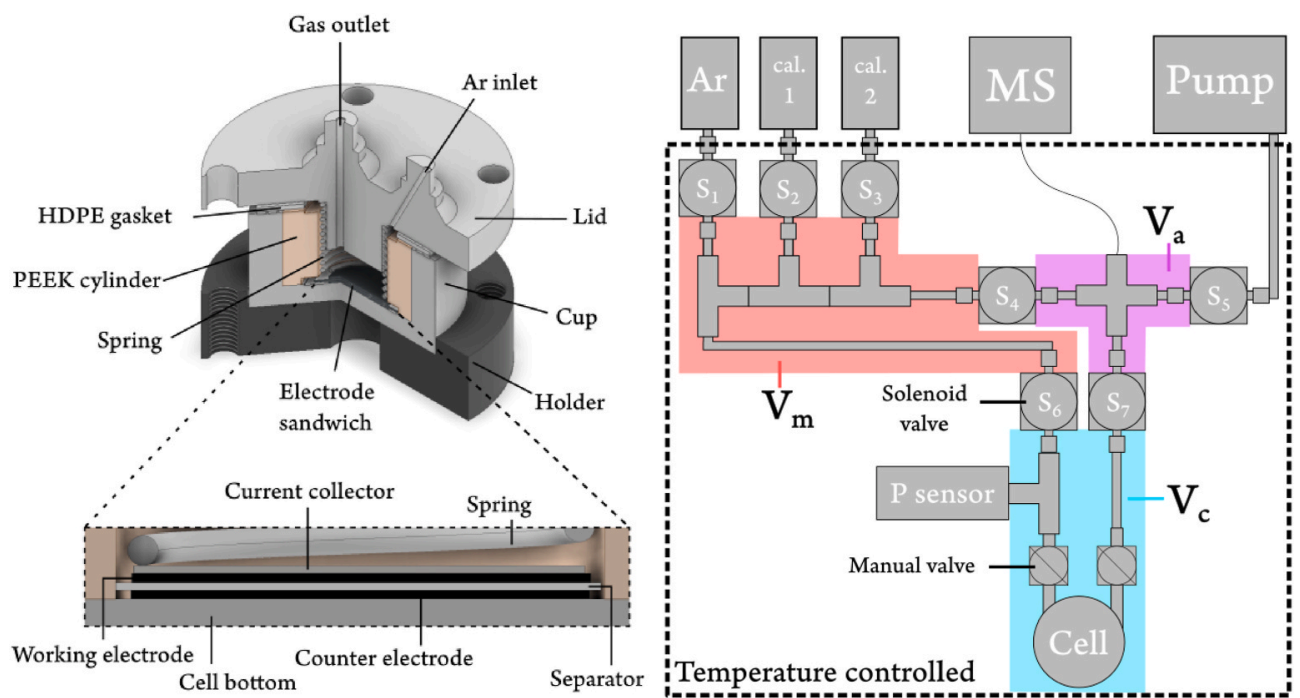

Fig. 1. Schematic representation of the dedicated electrochemical cell (left), and sampling system (right).

every experiment to determine $V_{c}$.

In order to calibrate the MS for quantitative analysis of evolving gases, pre-defined standards of known gas concentrations are used (2000 ppm $\mathrm{O}_{2}$ in $\mathrm{Ar}$, a mix of $2000 \mathrm{ppm} \mathrm{H}_{2}$ and $4000 \mathrm{ppm} \mathrm{CO}_{2}$, and $2000 \mathrm{ppm} \mathrm{C}_{2} \mathrm{H}_{4}$ in $\mathrm{Ar}$, all from Air Liquide). Each calibration gas is sequentially flushed in $V_{a}$ and the respective ion currents $\widehat{I}$ are recorded at mass-to-charge ratio $(\mathrm{m} / \mathrm{z})$ channels at which each gas of interest induces its strongest contribution (e.g. $m / z=32$ for $\mathrm{O}_{2}, 28$ and 44 for $\mathrm{CO}_{2}$, etc.). A compound that cannot be found as pre-defined standard is $\mathrm{PF}_{5}$ (or $\mathrm{POF}_{3}, m / z=85$, as it is usually observed), which instead is calibrated via thermal decomposition of $\mathrm{LiPF}_{6}$ in $V_{c}$. An adaptation to the method described by Solchenbach et al. [16] was utilized to achieve a calibration factor for $\mathrm{PF}_{5} / \mathrm{POF}_{3}$.

A calibration matrix $\bar{S}$ is generated considering the fragmentation behavior and mass discrimination for all gaseous species of interest, together with a background vector $\widehat{B}$ to account for electrolytes with different volatility. The calibration matrix is determined by solving the linear equation system:

$\widehat{I}=\bar{S} \widehat{x}+\widehat{B}$

where $\widehat{x}$ is the partial pressure vector defined by the fraction of each compound in the analyzed standard gas mixture. Each MS configuration displays its own intrinsic $m / z$ specific background due to noise in the electric circuitry and minute leaks, such as back-diffusion of air through the gas sampling and pump systems. The procedure of calibration of MS ion currents with gas standards described above is common in the field of applied mass spectrometry and the interested reader is, e.g., referred to the book from S. J. Ashton [17].

\subsection{Operation}

Before an experiment the sampling system is purged with carrier gas and pumped to vacuum several times to remove possible contaminations in the system. After purging, the manual vents on the cell are opened and the pressure in $V_{c}$ is equilibrated $(\sim 1.1$ bar abs.) with the rest of the sampling system. The cell cup and lid are connected to the potentiostat (Astrol Bat-Small, Switzerland).

The operation starts with the triggering of the electrochemical and gas measurement programs outlined below. Gas evolution is monitored by measuring total pressure of the cell continuously with the pressure transducer and recording the partial pressures of the cell at constant time intervals with the MS. A partial pressure measurement sequence starts by first evacuating $V_{a}$ with the pump by keeping $S_{5}$ open for $2 \mathrm{~s}$.
Subsequently the valves $S_{1-6-7}$ open for $5 \mathrm{~s}$, thus letting the gas in $V_{c}$ expand into $V_{a}$ while fresh Ar from $V_{m}$ and the Ar gas bottle at the same time flows into $V_{c}$, replacing the extracted gas. The extracted gas present in $V_{a}$ is sampled by the gas inlet to the MS until stable ion currents are recorded. The retention time of the capillary gas inlet is several seconds, which is acceptable since measurements occur at most every $10 \mathrm{~min}$. The partial pressures of the individual gases are determined by entering the recorded $\widehat{I}$ into Eq. (2) and solving for $\widehat{x}$. The number of mols, $n$, of the individual gas species are calculated by solving the Ideal gas law:

$\widehat{x} P_{\text {tot }} V_{c}=\widehat{n} R T$

where $R$ is the gas constant, $P_{\text {tot }}$ the total pressure from the transducer, and $T$ the temperature. The ideal gas conditions are assumed to be fulfilled, since the evolving gases are strongly diluted in $\operatorname{Ar}(>99 \%)$. The gas evolution rate $k_{i}$ at measurement point $\mathrm{i}$ is the ratio of the generated mols of gas $\Delta n_{i, i-1}$ between two partial pressure measurement times, $t_{i}$ and $t_{i-1}$ according to:

$\widehat{k}_{i}^{M S}=\frac{\Delta n_{i, i-1}^{M S}}{\Delta t_{i, i-1}}=\frac{\Delta n_{i, i-1}^{M S}}{t_{i}-t_{i-1}}$

where

$$
\begin{aligned}
& \widehat{n}_{i, i-1}^{M S}=\widehat{n}_{i}-\left(\widehat{n}_{i-1}-\widehat{n}_{i-1, a}\right) \\
& \begin{array}{c}
=\frac{\widehat{x}_{i} P_{i, b e f o r e} V_{c}}{R T}-\left(\frac{\widehat{x}_{i-1} P_{i-1, b e f o r e} V_{c}}{R T}-\frac{\widehat{x}_{i-1} P_{i-1, \text { affer }} V_{a}}{R T}\right) \\
R T \\
=\widehat{x}_{i} P_{i, b e f o r e} V_{c} \\
R T
\end{array}
\end{aligned}
$$

Which takes the removed and sampled mols of gas $\widehat{n}_{i-1, a}$ from the cell into account. The total cell pressures $P_{i, \text { before }}$ and $P_{i, \text { after }}$ are recorded before and after opening the valves for the partial pressure measurement point $i$. The total gas evolution rate $k_{i}^{P T}$ is estimated utilizing the pressure transducer, and similarly determined by substituting $\Delta \widehat{n}_{i, i-1}^{M S}$ in Eq. (4.1) for:

$\Delta n_{i, i-1}^{P T}=\frac{\Delta P V_{c}}{R T}=\frac{V_{c}}{R T}\left(P_{i, \text { before }}-P_{i-1, a f t e r}\right)$

The sum of each gas evolution rate in $\widehat{k}_{i}^{\text {MS }}$ should ideally be equal to (but never exceed) $k_{i}^{P T}$ if all relevant partial pressures are considered. 


\subsection{Validation}

The OEMS setup described herein was validated with two different experiments, (I) sensitivity limitation test and (II) gas profiling during electrochemical testing of a LCO/G cell, with LCO/LFP and G/LFP cells as analytical support.

I. Sensitivity limitation test. The electrochemical cell was flushed thoroughly, filled with $\mathrm{O}_{2}$ calibration gas (2000 ppm in Ar), and equilibrated for $30 \mathrm{~min}$. The partial pressure of $\mathrm{O}_{2}$ in the cell was sampled every $15 \mathrm{~min}$. Please note, since no gas evolution occurs inside the cell the partial pressure of $\mathrm{O}_{2}$ is expected to decrease as gas samples are extracted and replaced with fresh Ar. The calibration gas dilution was conducted two times: First, with an empty electrochemical cell only containing the calibration gas as a blank. Second, a glass fiber separator (Whatman, UK) soaked in $200 \mu \mathrm{L}$ LP40 (1 M LiPF 6 EC:DEC 1:1, Gotion, US) electrolyte was added to the empty cell before it was flushed, filled with $\mathrm{O}_{2}$ calibration gas, and the gas sampling started.

II. Gas profiling during electrochemical testing of $L C O / G$ cell. The G electrode was prepared by mixing $93 \mathrm{w} \%$ graphite powder (Timrex SLP30, Switzerland) together with 2 w\% super C65 (Imerys, Switzerland), and 5 w\% PVDF (Kynar Flex 2801 HPF, Arkema, France) binder in NMP solution. The solution was mixed for $30 \mathrm{~min}$ at $25 \mathrm{~Hz}$ (MM 400, Retsch, Germany). The slurry was coated on a stainless steel mesh $(212 / 90 \mu \mathrm{m}$, Bopp AG) with a $150 \mu \mathrm{m}$ gap applicator. The coating was dried in a ventilated oven before punched into $18 \mathrm{~mm}$ disks ( $\mathrm{m}_{\text {active }}$ material $=19.6 \mathrm{mg}$ ). The LCO electrode was prepared by mixing $80 \mathrm{w} \%$ LCO powder (Sigma-A. $99.8 \%$ trace metal basis) together with $10 \mathrm{w} \%$ super C65 (Imerys) and 10 w\% PVdF (Kynar Flex $2801 \mathrm{HPF}$ ) binder in NMP solution. The LCO based slurry was mixed for $30 \mathrm{~min}$ at $25 \mathrm{~Hz}$ (MM 400 , Retsch) before coated on a stainless steel mesh $(212 / 90 \mu \mathrm{m}$, Bopp AG), using a $100 \mu \mathrm{m}$ gap applicator. The LCO electrodes were punched into $15 \mathrm{~mm}$ disks ( $\mathrm{m}_{\text {active material }}=24.0 \mathrm{mg}$ ). All electrodes and cell parts were dried at $120{ }^{\circ} \mathrm{C}$ for $12 \mathrm{~h}$ in a vacuum oven (Vacuo-temp, BuchHolm A/S, Denmark). Two $20 \mathrm{~mm}$ Celgard 2325 separators (Celgard LLC, US), dried at $70{ }^{\circ} \mathrm{C}$ for $12 \mathrm{~h}$, were stacked in between the working and counter electrode during operation. The electrode sandwich was soaked in $200 \mu \mathrm{L} \mathrm{LP} 40$. The G electrode was used as counter electrode on the bottom of the cup. The LCO/G cell was electrochemically tested using cyclic voltammetry (CV) after it had rested at open circuit potential for $1.5 \mathrm{~h}$. The cell was cycled two cycles at a scan rate of $0.1 \mathrm{mV} / \mathrm{s}$ between $4.85 \mathrm{~V}$ and $2.55 \mathrm{~V}$.

The LCO/LFP and G/LFP cells were studied as analytical support for the LCO/G cell. The cell assembly and electrodes were prepared identically to the LCO/G cell, with the exception of the G electrode diameter, which was $15 \mathrm{~mm}$ instead of $18 \mathrm{~mm}$. The LFP electrodes were obtained as sheets $\left(3.5 \mathrm{mAhcm}^{-2}\right.$ ) from Customcells (Germany) and punched to $20 \mathrm{~mm}$ disks. The LFP electrode was used as counter electrode on the bottom of the electrochemical cell. The support cells were cycled at 0.1 $\mathrm{mV} / \mathrm{s}$ between $1.45 \mathrm{~V}$ and $-0.35 \mathrm{~V}\left(\sim 4.95 \mathrm{~V}\right.$ and $\left.3.15 \mathrm{~V} v s . \mathrm{Li}^{+} / \mathrm{Li}\right)$ for the LCO/LFP cell, and between $3.45 \mathrm{~V}$ and $1.95 \mathrm{~V}(\sim 0.05 \mathrm{~V}$ and $1.55 \mathrm{~V}$ $v s . \mathrm{Li}^{+} / \mathrm{Li}$ ) for the G/LFP cell. Every $10 \mathrm{~min}$ both the total $P_{i}$ and partial $\widehat{x}_{i}$ pressures of the cells are sampled and from the difference in pressures at the previous sample point $i-1$ the respective gas evolution rates $\Delta n$ are calculated according to Eqs. (4.2) and (5).

\section{Results and discussion}

I. Sensitivity limitation test. Gas dilution experiments are performed in order to evaluate the linearity and lower detection limit of the cell partial pressure measurement. Since a gas sample volume $V_{a}$ is extracted from cell volume $V_{c}$ and replaced with pure Ar in every measurement point $i$, the reduction of $\mathrm{O}_{2}$ partial pressure $x_{i}^{\mathrm{O}_{2}}$ is expected according to:

$x_{i}^{O_{2}}=(2000 p p m) \times\left(1-\frac{V_{a}}{V_{c}}\right)^{i}$
Indeed, the results in Fig. 2 show that in both cases the $\mathrm{O}_{2}$ partial pressure declines logarithmically with a slope of $\left(1-V_{a} / V_{c}\right)$. Both the blank and LP40 cases achieve an excellent linearity $\left(\mathrm{R}^{2}>99.6 \%\right)$ down to about $10 \mathrm{ppm}$ with a maximum deviation less than $15 \%$. Although partial pressure measurements of $\mathrm{O}_{2}$ below $10 \mathrm{ppm}$ are principally achievable with our quadrupole MS, the background of our setup renders the precision insufficient in the single digit ppm range. Assuming a precision of $10 \mathrm{ppm}$ at low $\mathrm{O}_{2}$ partial pressures, the detection limit would correspond to a gas evolution rate in the order of $\sim 0.1 \mathrm{nmol} / \mathrm{min}$, even when an electrolyte (such as LP40) is present. However, each individual gas specie is measurable with a precision defined by the sensitivity of the MS, the background induced by cell chemistry $(\mathrm{m} / \mathrm{z}$ overlap and interference of other volatile products or solvents of the electrolyte) and the configuration of the setup (e.g. leakages). Low vapor pressure electrolyte solvents with less complex $m / z$ fragmentation patterns, and non-overlapping $m / z$ peaks with the recorded gaseous products are in this respect favorable to reduce background and improve sensitivity. Important to consider regarding more volatile electrolyte solvents is that frequent gas sampling during long-term experiments will influence the concentration of the solvents in the electrolyte, which in turn might have an effect on the electrochemistry. Further aspects possibly affecting the measurement of gas mixtures, such as interaction between individual gaseous species, may need to be considered and one has in the end to validate the experimental approach on a case-by-case basis.

II. Gas profiling during electrochemical testing of $L C O / G$ cell. The three Li-ion cell configurations LCO/G (A), G/LFP (B), and LCO/LFP (C) are shown in Fig. 3. Fig. 3A shows that the higher time resolution of the pressure transducer allows for a more frequent recording. The pressure increases continuously from $t_{i-1}$ to $t_{i}$, even in the absence of any gassing, because of the replacement of sampled Ar atmosphere at $50^{\circ} \mathrm{C}$ in the cell with fresh Ar from the gas source outside the thermostatic chamber. Further increases in $P$ due to electrochemically induced gas evolution can nevertheless be anticipated already from the total pressure $P-P_{0}$ evolution profile (Fig. 3A), especially during SEI formation and at elevated $E$. The gas evolution rate based on the total pressure $\left(\triangle P V_{c} / R T\right)$ and sum of partial pressures $\left(\sum \Delta n\right)$ in Fig. 3A agree reasonably well with each other assuring us of the accuracy of the measurement and that

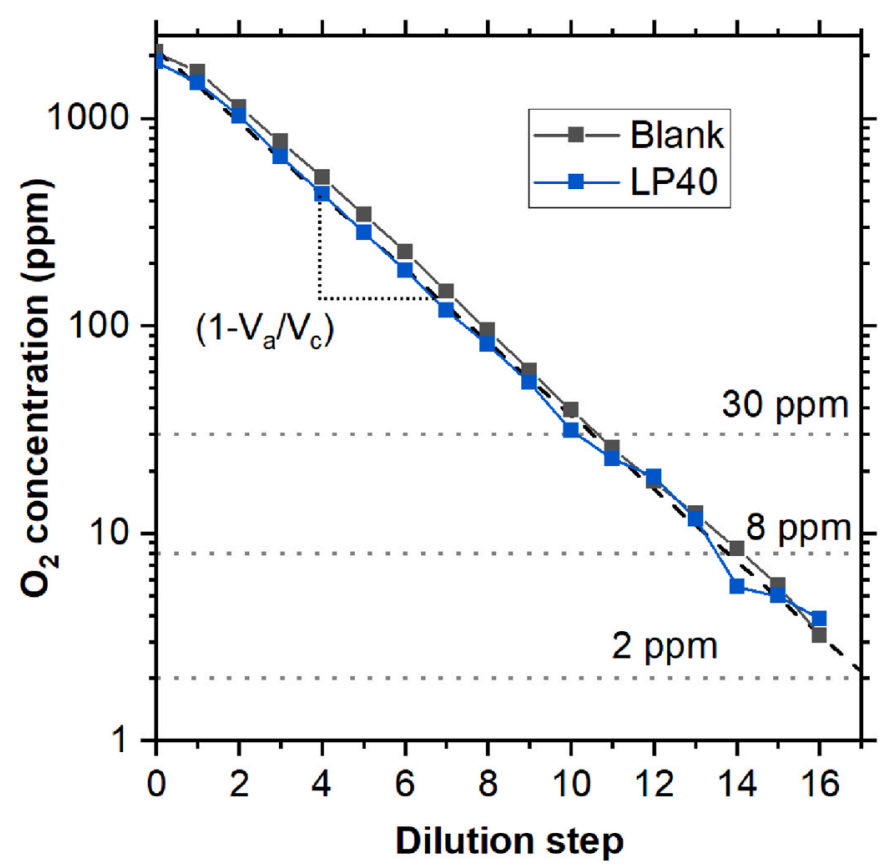

Fig. 2. Periodic dilution of $\mathrm{O}_{2}$ calibration gas in the electrochemical cell with different backgrounds; blank and LP40. 
A. LCO/G

$\because \mathrm{H}_{2}=\mathrm{C}_{2} \mathrm{H}_{4} \rightarrow \mathrm{O}_{2}-\mathrm{CO}_{2}-\mathrm{POF}_{3} \cdots \Sigma \Delta n \cdots \Delta \mathrm{PV}_{\mathrm{c}} / \mathrm{RT}$

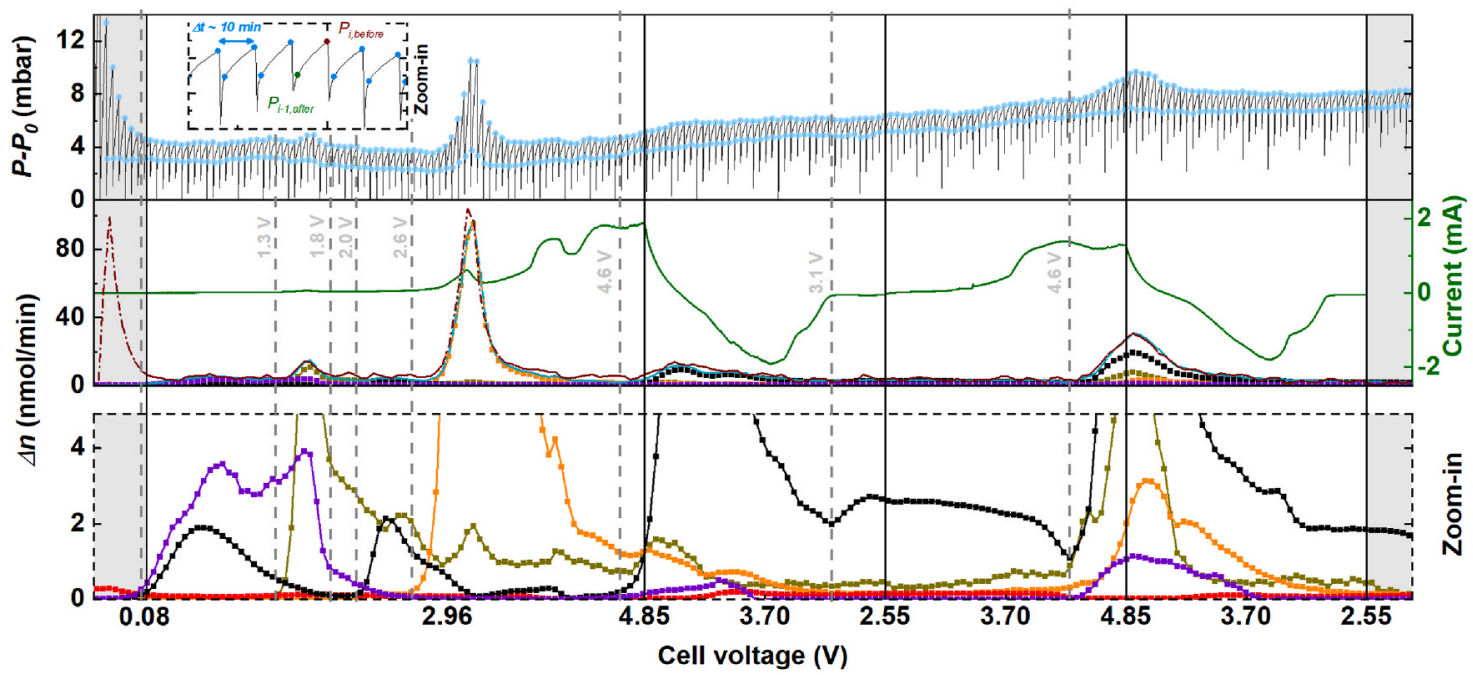

B. G/LFP

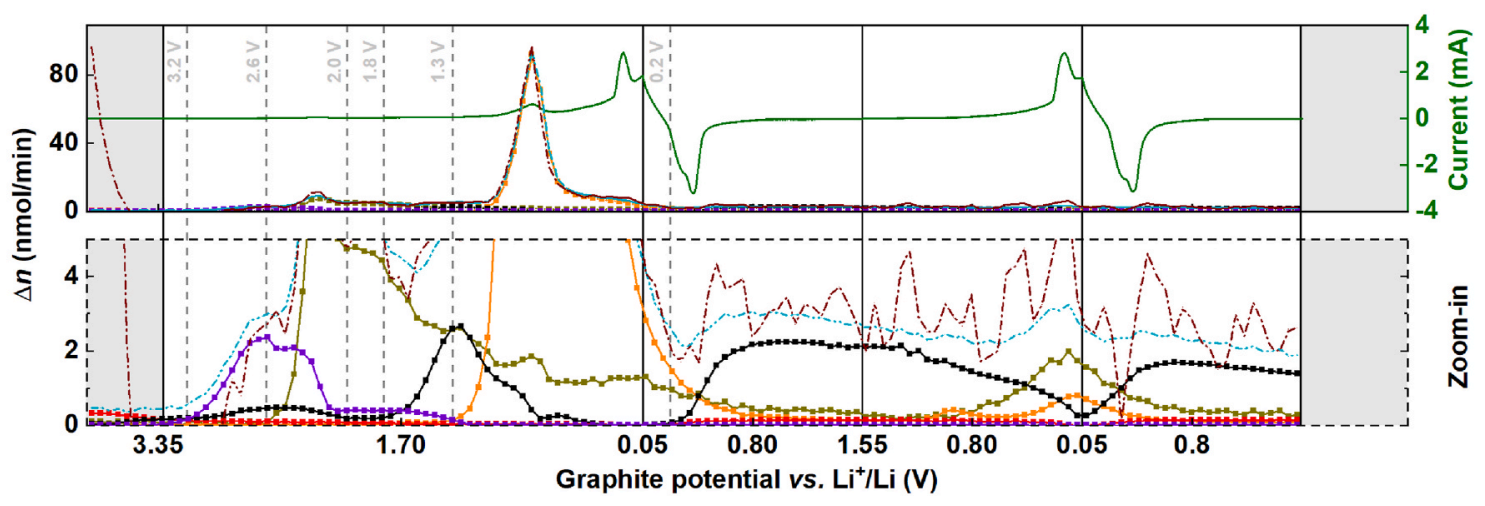

C. LCO/LFP

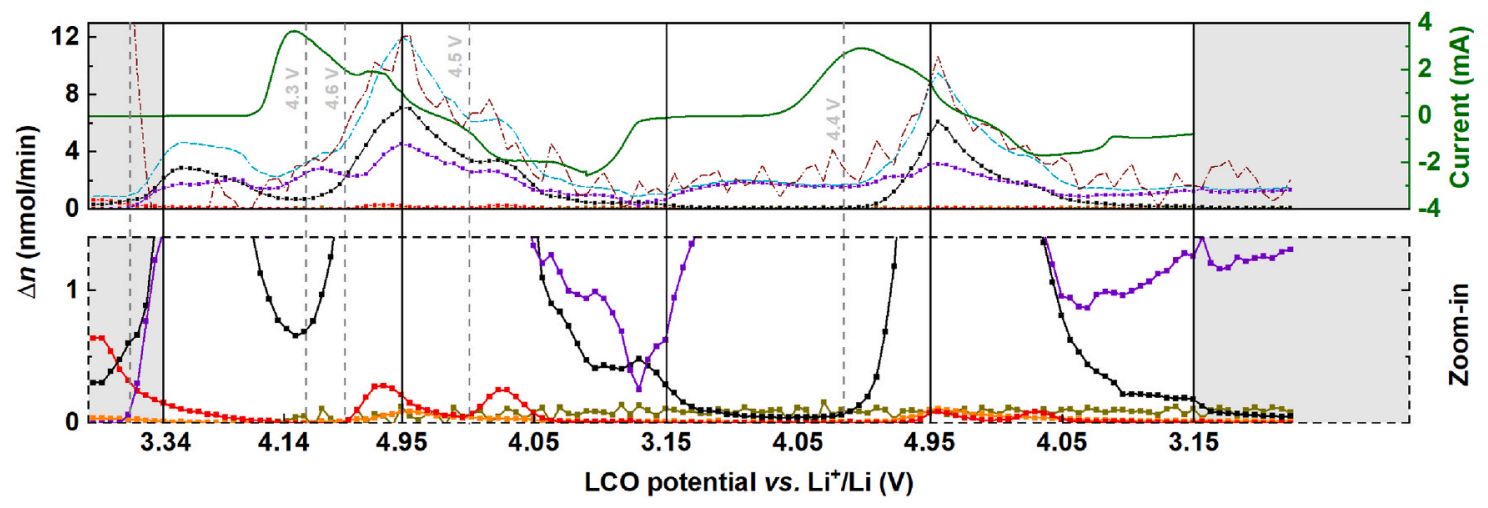

Fig. 3. Gas evolution and electrochemical profiles for LCO/G (A), G/LFP (B) and LCO/LFP (C), all in LP40 electrolyte during cyclic voltammetry at $50{ }^{\circ} \mathrm{C}$. The pressure profile for the LCO/G cell is included on top in (A), followed by gas and current profile during two cycles at scan rate $0.1 \mathrm{mV} / \mathrm{s}$ (middle), and a zoom-in on the gas profile (bottom). The gas and current profiles for G/LFP and LCO/LFP with zoom-in are shown in (B) and (C), respectively. Dashed grey vertical lines show where gas evolution reactions throughout the two cycles start. Solid black vertical lines show the vertex potentials. No potential is applied to the cell in areas dashed in grey. 
the dominating gas evolution processes are accounted for.

The onset, extent, and origin of the gases are discussed below in the order they appear. Immediately after connection and heating of the cell to $50{ }^{\circ} \mathrm{C}$, chemical decomposition of electrode/electrolyte impurities likely explain the minor amounts of $\mathrm{CO}_{2}$ and $\mathrm{POF}_{3}$. For instance, $\mathrm{Li}_{2} \mathrm{CO}_{3}$ residuals on LCO remaining from synthesis and/or air exposure may react with HF impurities of the electrolyte, as has earlier been proposed $[18,19]$ :

$2 \mathrm{HF}+\mathrm{Li}_{2} \mathrm{CO}_{3} \rightarrow \mathrm{H}_{2} \mathrm{O}+2 \mathrm{LiF}+\mathrm{CO}_{2}$

Indeed, there is initially more $\mathrm{CO}_{2}$ evolving when $\mathrm{LCO}$ is present (compare Fig. 3A and $\mathrm{C}$ with $\mathrm{B}$ ). Carbon dioxide evolution could also be attributed to thermally triggered EC hydrolysis by $\mathrm{H}_{2} \mathrm{O}$ formed in Rxn (7) or already present as impurity (e.g. due to insufficient drying of cell components), which would in addition lead to the formation of ethylene glycol (EG) [20]:

$\mathrm{H}_{2} \mathrm{O}+\mathrm{EC} \rightarrow \mathrm{CO}_{2}+\mathrm{EG}$

Water may also slowly react with electrolyte $\mathrm{PF}_{6}^{-}[21]$ :

$\mathrm{H}_{2} \mathrm{O}+\mathrm{LiPF}_{6} \rightarrow 2 \mathrm{HF}+\mathrm{POF}_{3}+\mathrm{LiF}$

thus explaining the concomitant evolution of $\mathrm{POF}_{3}$. Protons are known to destabilize the $\mathrm{PF}_{6}^{-}$anion [16], forming an auto-catalyzed salt decomposition cycle:

$\mathrm{H}^{+}+\mathrm{PF}_{6}^{-} \rightarrow \mathrm{HF}+\mathrm{PF}_{5}$ (observed as $\mathrm{POF}_{3}$ )

The evolution of $\mathrm{PF}_{5}$ is however never observed since $\mathrm{PF}_{5}$ reacts rapidly with the environment to form $\mathrm{POF}_{3}$ as previously confirmed by Solchenbach et al. [16] and also by us when calibrating the MS for $\mathrm{POF}_{3}$. A combination of Rxns (7-10) would hence explain why the initially accelerating evolution of $\mathrm{CO}_{2}$ and $\mathrm{POF}_{3}$ is only interrupted by the onset of electrochemistry. A very minor amount of $\mathrm{O}_{2}$ is included into the cell upon connection and gradually purged out. The gas evolution within the cell changes in nature once electrochemistry is initiated. Clearly, the SEI formation on the negative $\mathrm{G}$ electrode dominates the gassing (compare Fig. 3A and B with C), but several details of the process can be discerned by a systematic comparison of the evolution of the various gases associated with the three electrode configurations in Fig. 3A-C. During the first increasing polarization sweep the evolution of $\mathrm{POF}_{3}$ drops once $\mathrm{H}_{2}$ evolves (at $1.3 \mathrm{~V}$ in Fig. 3A and at 2.6 V in Fig. 3B) likely as a result of $\mathrm{H}^{+}$ reduction at the $\mathrm{G}$ electrode:

$\mathrm{H}^{+}+\mathrm{e}^{-} \rightarrow \frac{1}{2} \mathrm{H}_{2}$

and subsequent suppression of the auto-catalytic Rxn (10). The integrated $\mathrm{H}_{2}$ would correspond to a proton concentration of $\sim 93 \mathrm{ppm}$ in the electrolyte of the $\mathrm{LCO} / G$ full-cell. The link between salt degradation (and $\mathrm{POF}_{3}$ evolution) and proton concentration is supported by the fact that considerably more $\mathrm{POF}_{3}$ is observed for the cell based on LCO/LFP compared to the cells containing a reductive $\mathrm{G}$ anode. The $\mathrm{H}^{+}$reduction is likely followed by reduction of residual water (at $1.9 \mathrm{~V}$ in Figs. $3 \mathrm{~A}$ and 2.0 V in Fig. 3B):

$\mathrm{H}_{2} \mathrm{O}+\mathrm{e}^{-} \rightarrow \mathrm{OH}^{-}+\frac{1}{2} \mathrm{H}_{2}$

The integrated $\mathrm{H}_{2}$ would correspond to $\sim 54 \mathrm{ppm}$ of $\mathrm{H}_{2} \mathrm{O}$ in the electrolyte of the LCO/G cell. Both $\mathrm{HF}$ and $\mathrm{H}_{2} \mathrm{O}$ concentrations of the electrolyte were measured separately, via free F- ion sensitivity probe [22] and Karl- Fischer titration, before cell assembly and found to be 17 and $14 \mathrm{ppm}$, respectively. Considering the challenge of a fully complete drying of the various electrode and cell components before assembly, the magnitude of the $\mathrm{H}_{2}$ evolution is expected. In addition, the chemical Rxns (7-10) increase the $\mathrm{H}^{+}$and $\mathrm{H}_{2} \mathrm{O}$ concentrations further before cycling. The sequential reduction of first $\mathrm{H}^{+}$and then $\mathrm{H}_{2} \mathrm{O}$ is supported by parallel increase in $\mathrm{CO}_{2}$ evolution during the 2 nd $\mathrm{H}_{2}$ evolution peak.
The $\mathrm{OH}^{-}$generated in $\mathrm{Rxn}$ (12) is known to catalyze the ring-opening of EC (similar to Rxn (8)), which results in $\mathrm{CO}_{2}$ and polyEG ${ }^{-}$[20]:

$\mathrm{EC}+\mathrm{OH}^{-} \rightarrow$ polyEG $^{-}+\mathrm{CO}_{2}$

Later during the same potential sweep (at $2.6 \mathrm{~V}$ in Figs. $3 \mathrm{~A}$ and $1.3 \mathrm{~V}$ in Fig. 3B), a major evolution of $\mathrm{C}_{2} \mathrm{H}_{4}$ is triggered by EC reduction [23, 24]:

$\mathrm{EC}+\mathrm{Li}^{+}+\mathrm{e}^{-} \rightarrow \frac{1}{2} \mathrm{C}_{2} \mathrm{H}_{4}+\frac{1}{2} \mathrm{C}_{4} \mathrm{O}_{6} \mathrm{H}_{4} \mathrm{Li}_{2}($ LEDC $)$

which is further supported by the observed $\sim 2 \mathrm{e}^{-} / \mathrm{C}_{2} \mathrm{H}_{4}$ ratio. Both $\mathrm{C}_{2} \mathrm{H}_{4}$ and LEDC are generally expected to form during SEI formation on graphite in EC based electrolytes. If we assume a uniform coverage of LEDC over the whole graphite surface $\left(\mathrm{S}_{\mathrm{BET}} \sim 7.5 \mathrm{~m}^{2} / \mathrm{g}\right)$, we may estimate a thickness of the LEDC layer to $4.5 \mathrm{~nm}$ by integrating the amount of $\mathrm{C}_{2} \mathrm{H}_{4}$ formed $(6.1 \mu \mathrm{mol})$, then multiplying the same number by the molar mass of LEDC $(162 \mathrm{~g} / \mathrm{mol})$ and dividing by an assumed density of LEDC $(\sim 1.5 \mathrm{~g} / \mathrm{mL})$ as well as the area of the graphite electrode $(\sim 0.15$ $\mathrm{m}^{2}$ ). Such a nm-thick SEI layer would be sufficient to suppress further EC reduction.

A second $\mathrm{C}_{2} \mathrm{H}_{4}$ peak is seen at the upper vertex potential, which is likely a result of further SEI formation, due to graphite expansion and contraction caused by $\mathrm{Li}^{+}$de-/insertion [25]. Minor amounts of $\mathrm{H}_{2}$ evolve with a slight offset from $\mathrm{C}_{2} \mathrm{H}_{4}$ and might originate from several processes, such as reduction of remaining $\mathrm{H}^{+} / \mathrm{H}_{2} \mathrm{O}$ impurities and/or the glycols formed in Rxn (8) and (13) at the strongly negatively polarized graphite [26,27].

At elevated potentials were electrolyte oxidation may occur an increase in $\mathrm{H}_{2}$ gas evolution is present. A likely reaction is oxidized electrolyte species $\left(\mathrm{RH}^{+}\right)$diffuse to the reductive graphite, where $\mathrm{H}_{2}$ is formed [28]:

$\mathrm{RH}^{+}+\mathrm{e}^{-} \rightarrow \mathrm{R}+\frac{1}{2} \mathrm{H}_{2}$

The evolution rates of $\mathrm{O}_{2}, \mathrm{CO}_{2}$, and $\mathrm{POF}_{3}$ are observed to increase when the overcharge of LCO onsets ( $>4.6 \mathrm{~V}$ in Fig. 3A and C). At low degrees of lithiation $(\mathrm{x}<0.4), \mathrm{L}_{\mathrm{x}} \mathrm{CO}$ is known to degrade whereby the delithiated phase $\mathrm{CoO}_{2}$ is thermally triggered to transform into spinel $\mathrm{Co}_{3} \mathrm{O}_{4}$ and rock-salt $\mathrm{CoO}$ type phases:

$\mathrm{CoO}_{2} \rightarrow \mathrm{Co}_{3} \mathrm{O}_{4} / \mathrm{CoO}+\mathrm{O}$

Integration of the current in Fig. $3 \mathrm{~A}$ and $\mathrm{C}$ shows that the associated gases onset when $\mathrm{Li}_{0.39} \mathrm{CoO}_{2}$ is reached, which agrees with previous structural analysis studies [29]. However, only a minor fraction of the leaving oxygen is likely to recombine forming $\mathrm{O}_{2}\left(\sim 110 \mu \mathrm{mol} \mathrm{O}_{2} / \mathrm{mol}\right.$ LCO is observed here) since evolving $\mathrm{O}$ should be highly reactive, especially towards the electrolyte:

$\mathrm{EC}+\mathrm{O} \rightarrow \mathrm{CO}_{2}+\mathrm{H}^{+}+\mathrm{RO}$

The mere observation of $\mathrm{CO}_{2}$ and $\mathrm{POF}_{3}$ (likely triggered according to Rxn (10) by the release of protons) here is not sufficient to speculate neither on the nature of the leaving oxygen (e.g. atomic $\mathrm{O}$ radicals or singlet ${ }^{1} \mathrm{O}_{2}$ ) nor the composition of the RO electrolyte degradation products. However, studies showing similar gas behaviors have linked singlet ${ }^{1} \mathrm{O}_{2}$ to the process [30]. Less molecular $\mathrm{O}_{2}$ is observed in Fig. 3A compared to $\mathrm{C}$, which can be explained by $\mathrm{O}_{2}$ scavenged by the reductive graphite. Interestingly, during the reductive sweep a 2 nd $\mathrm{O}_{2}$ peak (and associated $\mathrm{CO}_{2}$ ) form, which supports the hypothesis that a certain compositional phase (or mix of phases) of $\mathrm{L}_{\mathrm{x}} \mathrm{CO}$ is vulnerable to structural degradation [31,32]. $\mathrm{O}_{2}$ release reoccurs during both oxidative and reductive sweep in the 2 nd cycle, which further evidences the existence of a certain $\mathrm{L}_{\mathrm{x}} \mathrm{CO}$ composition particularly prone to oxygen release.

Carbon dioxide is observed (Fig. 3A and B) throughout the two cycles after SEI formation and might stem from the continuous breakdown of LEDC (formed earlier in Rxn (14)) to form lithium ethyl monocarbonate 
(LEMC) [33]:

$\mathrm{LEDC} \rightarrow \mathrm{CO}_{2}+$ LEMC

As LEDC gradually converts into LEMC, the concentration of $\mathrm{CO}_{2}$ in the cell will decrease over time, as can be anticipated in Fig. $3 \mathrm{~A}$ and $\mathrm{B}$. The $\mathrm{CO}_{2}$ evolution rate is however observed to drop at low potentials, especially in the 1st cycle, which likely is a result of $\mathrm{CO}_{2}$ consumption (e. g. by direct reduction on the graphite as outlined by Schwenke et al. [34]) immediately after its formation.

\section{Conclusions}

A novel OEMS setup exploiting simultaneous partial and total pressure monitoring is developed, validated and presented herein. Details of calibration and measurement procedures considering fragmentation, mass discrimination, and total gas evolution rates are described and discussed. Proof-of-concept experiments involving three Li-ion cell configurations demonstrate the unique ability of the OEMS to confidently determine and quantify gas species evolving from either the positive or negative electrode in an electrolyte based on $1 \mathrm{M} \mathrm{LiPF}_{6}$ in 1:1 EC:DEC. A gas study of a LCO/G cell has never been showcased on such a detailed level before, where both potential- and thermal-induced sidereactions are considered, under what circumstance they trigger, and in what quantity the resulting gases evolve. The major gas evolving during the formation cycle is $\mathrm{C}_{2} \mathrm{H}_{4}$ (39.1\% of the integrated total), which originates mostly from the SEI formation on the negative graphite electrode. Carbon dioxide is the second major evolving gas (37.2\%), where $\mathrm{CO}_{2}$ is seen in the initial stages of the cycling where residual $\mathrm{Li}_{2} \mathrm{CO}_{3}$ is decomposed, and later when $\mathrm{L}_{\mathrm{x}} \mathrm{CO}$ reaches a $\mathrm{x}<0.4$ lithiation degree and decomposes. Throughout the cycling when graphite is part of the configuration a continuous $\mathrm{CO}_{2}$ evolution is present, likely caused by thermally activated decomposition of products originating from SEI formation. Hydrogen gas (15.4\%) forms during initial residual $\mathrm{H}^{+}$and $\mathrm{H}_{2} \mathrm{O}$ reduction at the negative electrode, and during the SEI process. Hydrogen also evolves as a result of electrolyte solvent oxidation at the positive electrode and the subsequent diffusion and reduction of degradation products at the negative electrode. Both $\mathrm{POF}_{3}(7.1 \%)$ and $\mathrm{O}_{2}(1.3 \%)$ gases are present to a lesser extent, of which the latter is formed from the release of highly reactive oxygen from LCO and its sidereactions with the electrolyte. Phosphorus pentafluoride (observed as $\mathrm{POF}_{3}$ ) is also formed due to $\mathrm{LiPF}_{6}$ thermal reactions with $\mathrm{H}_{2} \mathrm{O}$ and $\mathrm{H}^{+}$. Importantly, a large fraction of the gas is not directly electrochemically induced, but rather evolve as a result of thermally triggered reactions in the electrolyte phase. However, the side-products thus formed may for instance again interact with the electrode/electrolyte interface and henceforth be a key constituent in the complex formation process of the SEI or equally well just simply add to the accumulation of ineffective resistive junk in the cell.

Several advantages of combining partial and total pressure monitoring may be immediately discerned. First, $P_{\text {tot }}$ validates proper quantification of partial pressures. Second, major gas species of unknown composition may be identified and quantified simply by comparing the $\mathrm{n}_{\text {tot }}$ and $\widehat{\mathrm{n}}_{\mathrm{i}}$ gas evolution profiles. Third, model experiments generating known but so far unquantified gaseous products may be conducted to calibrate the MS for more complex experiments. The presented OEMS setup furthermore provides unique opportunities for longer-term online gas evolution measurements (days or weeks with pressure transducer) without disturbance of cell chemistry introduced by unnecessary continuous gas removal implemented in most systems developed so far. Similarly, to the development by McCloskey et al. at IBM [5] and He et al. at PSI [12], the setup presented herein offers the possibility to connect multiple cells, which allows for more effective use of the MS for partial pressure determination only when necessary. Finally, the current setup may straightforwardly be extended to also include a gas chromatographic column before the inlet to the MS, which would significantly facilitate the identification of minor gases, but such adaptions remains here as a future outlook.

\section{Author contributions}

E.J.B conceptualized the project. Experiments and data analysis were conducted by R.L. The manuscript was written through contributions of all authors. All authors have approved the final version of the manuscript.

\section{Notes}

The authors declare no competing financial interest.

\section{Declaration of competing interest}

The authors declare that they have no known competing financial interests or personal relationships that could have appeared to influence the work reported in this paper.

\section{Acknowledgments}

The authors acknowledge Knut and Alice Wallenberg (KAW) Foundation (Grant 2017.0204) and Swedish Research Council (2016-04069) for financial support. StandUp for Energy is acknowledged for base funding.

The authors especially acknowledge Ming-Long He, Hermann Kaiser, and Petr Novák at Paul Scherrer Institute in Switzerland for their contributions to the earlier versions of the OEMS setup outlined above. Leif Edlén is gratefully acknowledged for technical assistance.

\section{References}

[1] K.A. Nier, A.L. Yergey, P. Jane Gale, A general chronicle of mass spectrometry and guide to the scope of the volume, in: The Encyclopedia of Mass Spectrometry, Elsevier, 2016, pp. 7-12, https://doi.org/10.1016/B978-0-08-043848-1.00003-1.

[2] B.B. Berkes, A. Jozwiuk, M. Vracar, H. Sommer, T. Brezesinski, J. Janek, Online continuous flow differential electrochemical mass spectrometry with a realistic battery setup for high-precision, long-term cycling tests, Anal. Chem. 87 (12) (2015) 5878-5883, https://doi.org/10.1021/acs.analchem.5b01237.

[3] H. Wang, E. Rus, H.D. Abruna, New double-band-electrode channel flow differential electrochemical mass spectrometry cell: application for detecting product formation during methanol electrooxidation, Anal. Chem. 82 (11) (2010) 4319-4324, https://doi.org/10.1021/ac100320a.

[4] N. Tsiouvaras, S. Meini, I. Buchberger, H.A. Gasteiger, A novel on-line mass spectrometer design for the study of multiple charging cycles of a $\mathrm{Li}^{-} \mathrm{O}_{2}$ battery 160, 2013, pp. 1-7, https://doi.org/10.1149/2.042303jes (3).

[5] B.D. McCloskey, D.S. Bethune, R.M. Shelby, G. Girishkumar, A.C. Luntz, Solvents critical role in nonaqueous lithium-oxygen battery electrochemistry, J. Phys. Chem. Lett. 2 (10) (2011) 1161-1166, https://doi.org/10.1021/jz200352v.

[6] R. Imhof, P. Novák, In situ investigation of the electrochemical reduction of carbonate electrolyte solutions at graphite electrodes, October 145 (4) (1998) 1081-1087, https://doi.org/10.1149/1.1838201.

[7] A.M. Tripathi, W.N. Su, B. Hwang, J. In situ analytical techniques for battery interface analysis, Chem. Soc. Rev. 47 (3) (2018) 736-751, https://doi.org/ 10.1039/c7cs00180k

[8] S. Bruckenstein, R.R. Gadde, Use of a porous electrode for in situ mass spectrometric determination of volatile electrode reaction products, J. Am. Chem. Soc. 93 (3) (1971) 793-794, https://doi.org/10.1021/ja00732a049.

[9] O. Wolter, J. Heitbaum, Differential electrochemical mass spectroscopy (DEMS) - a new method for the study of electrode processes, Berichte der Bunsengesellschaft für Phys. Chemie 6 (1984) 2-6, https://doi.org/10.1002/bbpc.19840880103.

[10] H. Baltruschat, Differential electrochemical mass spectrometry, J. Am. Soc. Mass Spectrom. 15 (12) (2004) 1693-1706, https://doi.org/10.1016/j. jasms.2004.09.011.

[11] P. Novák, D. Goers, L. Hardwick, M. Holzapfel, W. Scheifele, J. Ufheil, A. Würsig, Advanced in situ characterization methods applied to carbonaceous materials, J. Power Sources 146 (1-2) (2005) 15-20, https://doi.org/10.1016/j. jpowsour.2005.03.129.

[12] M. He. Elucidating Interface Reactions in Li-Ion Batteries and Supercapacitors by in Situ Gas Analysis, ETH Zurich, 2016,, https://doi.org/10.3929/ethz-a-010852357.

[13] M. He, L. Boulet-Roblin, P. Borel, C. Tessier, P. Novák, C. Villevieille, E.J. Berg, Effects of solvent, lithium salt, and temperature on stability of carbonate-based electrolytes for $5.0 \mathrm{~V} \mathrm{LiNi}_{0.5} \mathrm{Mn}_{1.5} \mathrm{O}_{4}$ electrode S, J. Electrochem. Soc. 163 (2) (2016) A83-A89, https://doi.org/10.1149/2.0201602jes. 
[14] J. Self, C.P. Aiken, R. Petibon, J.R. Dahn, Survey of gas expansion in Li-ion NMC pouch cells, J. Electrochem. Soc. 162 (6) (2015) A796-A802, https://doi.org/ 10.1149/2.0081506jes.

[15] N. Laszczynski, S. Solchenbach, H.A. Gasteiger, B.L. Lucht, Understanding electrolyte decomposition of graphite/NCM811 cells at elevated operating voltage, J. Electrochem. Soc. 166 (10) (2019) A1853-A1859, https://doi.org/10.1149/ 2.0571910jes.

[16] S. Solchenbach, M. Metzger, M. Egawa, H. Beyer, H.A. Gasteiger, Quantification of $\mathrm{PF}_{5}$ and $\mathrm{POF}_{3}$ from side reactions of $\mathrm{LiPF}_{6}$ in Li-ion batteries, J. Electrochem. Soc 165 (13) (2018) A3022-A3028, https://doi.org/10.1149/2.0481813jes.

[17] S.J. Ashton, Design, construction and Research application of a differenctial electrochemical mass spectrometer (DEMS), TU-München (2012), https://doi.org/ 10.1007/978-3-642-30550-4.

[18] S. Leroy, H. Martinez, R. Dedryvère, D. Lemordant, D. Gonbeau, Influence of the lithium salt nature over the surface film formation on a graphite electrode in $\mathrm{Li}$-ion batteries: an XPS study, Appl. Surf. Sci. 253 (11) (2007) 4895-4905, https://doi. org/10.1016/j.apsusc.2006.10.071.

[19] K. Kanamura, H. Tamura, S. Shiraishi, Z. Takehara, XPS analysis of lithium surfaces following immersion in various solvents containing $\mathrm{LiBF}_{4}$, J. Electrochem. Soc. 142 (2) (1995) 340, https://doi.org/10.1149/1.2044000.

[20] M. Metzger, B. Strehle, S. Solchenbach, H.A. Gasteiger, Hydrolysis of ethylene carbonate with water and hydroxide under battery operating conditions 163, 2016, pp. 1219-1225, https://doi.org/10.1149/2.0411607jes (7).

[21] C.G. Barlow, Reaction of water with hexafluorophosphates and with Li bis (Perfluoroethylsulfonyl)Imide salt, Electrochem. Solid State Lett. 2 (8) (1999) 362-364, https://doi.org/10.1149/1.1390838.

[22] D. Strmcnik, I.E. Castelli, J.G. Connell, D. Haering, M. Zorko, P. Martins, P. P. Lopes, B. Genorio, T. Østergaard, H.A. Gasteiger, Electrocatalytic transformation of $\mathrm{HF}$ impurity to $\mathrm{H}_{2}$ and LiF in lithium-ion batteries, Nat. Catal. 1 (4) (2018) 255-262, https://doi.org/10.1038/s41929-018-0047-z.

[23] M. Lanz, P. Novák, DEMS study of gas evolution at thick graphite electrodes for lithium-ion batteries: the effect of $\gamma$-butyrolactone, J. Power Sources $102(1-2)$ (2001) 277-282, https://doi.org/10.1016/S0378-7753(01)00826-6.

[24] S.J. An, J. Li, C. Daniel, D. Mohanty, S. Nagpure, D.L. Wood, The state of understanding of the lithium-ion-battery graphite solid electrolyte interphase (SEI) and its relationship to formation cycling, Carbon N. Y. 105 (2016) 52-76, https:// doi.org/10.1016/j.carbon.2016.04.008.
[25] A.J. Louli, J. Li, S. Trussler, C.R. Fell, J.R. Dahn, Volume, pressure and thickness evolution of Li-ion pouch cells with silicon-composite negative electrodes, J. Electrochem. Soc. 164 (12) (2017) A2689-A2696, https://doi.org/10.1149/ 2.1691712jes.

[26] P. Novák, F. Joho, R. Imhof, J.C. Panitz, O. Haas, In situ investigation of the interaction between graphite and electrolyte solutions, J. Power Sources 81-82 (1999) 212-216, https://doi.org/10.1016/S0378-7753(99)00119-6.

[27] R. Bernhard, M. Metzger, H.A. Gasteiger, Gas evolution at graphite anodes depending on electrolyte water content and SEI quality studied by on-line electrochemical mass spectrometry, J. Electrochem. Soc. 162 (10) (2015) A1984-A1989, https://doi.org/10.1149/2.0191510jes.

[28] M. Metzger, B. Strehle, S. Solchenbach, H.A. Gasteiger, Origin of $\mathrm{H}_{2}$ evolution in LIBs: $\mathrm{H}_{2} \mathrm{O}$ reduction vs. Electrolyte oxidation, J. Electrochem. Soc. 163 (5) (2016) A798-A809, https://doi.org/10.1149/2.1151605jes.

[29] J. Kikkawa, S. Terada, A. Gunji, T. Nagai, K. Kurashima, K. Kimoto, Chemical states of overcharged $\mathrm{LiCoO}_{2}$ particle surfaces and interiors observed using electron energy-loss spectroscopy, J. Phys. Chem. C 119 (28) (2015) 15823-15830, https:// doi.org/10.1021/acs.jpcc.5b02303.

[30] J. Wandt, A.T.S. Freiberg, A. Ogrodnik, H.A. Gasteiger, Singlet oxygen evolution from layered transition metal oxide cathode materials and its implications for lithium-ion batteries, Mater. Today 21 (8) (2018) 825-833, https://doi.org/ 10.1016/j.mattod.2018.03.037.

[31] Z. Chen, Z. Lu, J.R. Dahn, Staging phase transitions in $\mathrm{Li}_{\mathrm{x}} \mathrm{CoO}_{2}$, J. Electrochem. Soc. 149 (12) (2002) A1604, https://doi.org/10.1149/1.1519850.

[32] a. Van der Ven, M.K. Aydinol, G. Ceder, G. Kresse, J. Hafner, First-principles investigation of phase stability in $\mathrm{Li}_{\mathrm{x}} \mathrm{CoO}_{2}$, Phys. Rev. B 58 (6) (1998) 2975-2987, https://doi.org/10.1103/PhysRevB.58.2975.

[33] J. Henschel, C. Peschel, S. Klein, F. Horsthemke, M. Winter, S. Nowak, Clarification of decomposition pathways in a state-of-the-art lithium ion battery electrolyte through ${ }^{13} \mathrm{C}$-labeling of electrolyte components, Angew. Chem. 132 (15) (2020) 6184-6193, https://doi.org/10.1002/ange.202000727.

[34] K.U. Schwenke, S. Solchenbach, J. Demeaux, B.L. Lucht, H.A. Gasteiger, The impact of $\mathrm{CO}_{2}$ evolved from VC and FEC during formation of graphite anodes in lithium-ion batteries, J. Electrochem. Soc. 166 (10) (2019) A2035-A2047, https:// doi.org/10.1149/2.0821910jes. 